\title{
Decomposition of Electricity Consumption Intensity of High Energy-consuming Industries in Shanxi Province Based on LMDI Method
}

\author{
Huiru Zhao, Nana Li \\ School of Economics and Management, North China Electric Power University, Beijing, China
}

Email address:

nancyli1007@163.com (Nana Li)

To cite this article:

Huiru Zhao, Nana Li. Decomposition of Electricity Consumption Intensity of High Energy-consuming Industries in Shanxi Province Based on LMDI Method. International Journal of Energy and Power Engineering. Special Issue: Current Energy Issues in China.

Vol. 4, No. 4-1, 2015, pp. 7-11. doi: 10.11648/j.ijepe.s.2015040401.12

\begin{abstract}
In this paper, the electricity consumption intensity of the high energy-consuming industries in Shanxi province from2007-2012 is decomposed based on LMDI method, in which the affecting factors involve structure effect and intensity effect. The results show that the structure adjustment of Shanxi province is the main driver which declines the electricity consumption intensity for high energy-consuming industries. For most industries, the structure effect declines the intensity with a high contribution proportion. Meanwhile, the contribution proportions of efficiency effect for most industries are less than the corresponding structure effect. The totla effect of each high energy-consuming industry is shown in table 4, in which the totoal effect of Non-ferrous metal smelting and rolling processing industry is relative higher than other industries, and the effect of Black metal smelting and rolling processing industry is just smaller than it.
\end{abstract}

Keywords: LMDI, Electricity Consumption Intensity, High Energy-consuming Industry, Structure Effect, Efficiency Effect

\section{Introduction}

As we all know, Shanxi is the most important base of energy and heavy chemical industries in China. With the increasing demand from home and abroad, high energyconsuming industries, such as coal, ferrous, nonferrous metals and chemicals have made great economic development. In recent years, the value added of high energyconsuming industries has been keeping a double-digit growth rate, which promotes the further growth of the economic development and electricity demand in Shanxi province. However, owning to the characteristics high emission, high pollution and high consuming for industry in Shanxi province, government gradually speeds up the adjustment of the energy consumption structure and improves the electricity efficiency. Therefore, research on the electricity consumption intensity is essential to promote the energy saving and emission reduction for high energy-consuming industries in Shanxi. There are multiple factors affecting the consumption intensity of electricity, which has attracted more and more researchers to analyse the impact of different factors based on decomposition. To the best of my knowledge, many decomposition techniques have been proposed to analyse the factors affecting the energy consumption and consumption intensity, including structure decomposition analysis (SDA) and index decomposition analysis (IDA) and so on. In addition, IDA contains of Laspeyre Index Decomposition and Divisia Index Decomposition, which has been widely applied into the research of price, energy and environment issues[1$6]$.

However, this method will produce interaction problem in the decomposition process, which makes deviations between decomposition results and practice, such as the problems of "Remainder" and "0" value. After that, The LMDI (Logarithmic Mean Divisia Index) method was proposed to solve this problem, which has been used by domestic and foreign scholars. The changes of energy intensity in China from 1980-2003 are dcomposed into technology improvement and structure change based on LMDI by Chunbo Ma[7]. In addition, the coal and oil consumptions in China from 1997-2002 are decomposed into production scale effect, structure effect and efficiency effect( Fengdan Shi, 2008)[8]. Yuhui Ou (2007) decomposed growth of Chinese energy consumption from 1985-2003 based on LMDI method[9].

Apparently, many researchers have been done to 
decompose the energy consumption and energy consumption intensity by domestic and foreign scholars. Nevertheless, little studies draw attention on the electricity consumption intensity of high energy-consuming industries. Therefore, in this paper, the LMDI method will be used to analyse the affecting factor of the electricity consumption intensity of high energy-consuming industries in Shanxi province.

\section{Methodology}

According to the definition of electricity consumption intensity, the electricity consumption intensity can be expressed as:

$$
I=\frac{E}{Q}=\sum_{i} \frac{E_{i}}{Q}=\sum_{i} \frac{Q_{i}}{Q} \frac{E_{i}}{Q_{i}}=\sum_{i} S_{i} I_{i}
$$

Where, I represents the overall electricity consumption intensity; $E$ represents overall output level; $E_{\mathrm{i}}$ is electricity consumption of sector i, $S_{i}=\frac{Q_{i}}{Q}$ and $I_{i}=\frac{E_{i}}{Q_{i}}$ are the activity share and electricity intensity of sector i, respectively, Therefore, the influence factors of electricity consumption intensity can be decomposed into two factors: industry structure and power intensity[10-11].

According to $\mathrm{Eq}$ (1), the changes of electricity consumption intensity from period $\mathrm{t}$ to period 0 can be decomposed into these two factors:

$$
\Delta I_{\text {tot }}=I^{T}-I^{0}=\sum_{i} S_{i}^{T} I_{i}^{T}-\sum_{i} S_{i}^{0} I_{i}^{0}=\Delta I_{s t r}+\Delta I_{\mathrm{int}}
$$

where,

$$
\begin{aligned}
& \Delta I_{\mathrm{str}}=\sum_{i} \frac{\frac{E_{i}^{T}}{Q^{T}}-\frac{E_{i}^{0}}{Q^{0}}}{\ln \frac{E_{i}^{T}}{Q^{T}}-\ln \frac{E_{i}^{0}}{Q^{0}}} \ln \left(\frac{S_{i}^{T}}{S_{i}^{0}}\right) \\
& \Delta I_{\mathrm{int}}=\sum_{i} \frac{\frac{E_{i}^{T}}{Q^{T}}-\frac{E_{i}^{0}}{Q^{0}}}{\ln \frac{E_{i}^{T}}{Q^{T}}-\ln \frac{E_{i}^{0}}{Q^{0}}} \ln \left(\frac{I_{i}^{T}}{I_{i}^{0}}\right)
\end{aligned}
$$

And

$$
D_{\text {tot }}=I^{T} / I^{0}=\sum_{i} S_{i}^{T} I_{i}^{T} / \sum_{i} S_{i}^{0} I_{i}^{0}=D_{s t r} D_{\mathrm{int}}
$$

where,

$$
\begin{gathered}
D_{s t r}=\exp \left(\sum_{i} \frac{\left(\frac{E_{i}^{T}}{Q^{T}}-\frac{E_{i}^{0}}{Q^{0}}\right) /\left(\ln \frac{E_{i}^{T}}{Q^{T}}-\ln \frac{E_{i}^{0}}{Q^{0}}\right)}{\left(I^{T}-I^{0}\right) /\left(\ln I^{T}-\ln I^{0}\right)} \ln \left(\frac{S_{i}^{T}}{S_{i}^{0}}\right)\right) \\
D_{\mathrm{int}}=\exp \left(\sum_{i} \frac{\left(\frac{E_{i}^{T}}{Q^{T}}-\frac{E_{i}^{0}}{Q^{0}}\right) /\left(\ln \frac{E_{i}^{T}}{Q^{T}}-\ln \frac{E_{i}^{0}}{Q^{0}}\right)}{\left(I^{T}-I^{0}\right) /\left(\ln I^{T}-\ln I^{0}\right)} \ln \left(\frac{I_{i}^{T}}{I_{i}^{0}}\right)\right)
\end{gathered}
$$

Above $\mathrm{Eq}(2)$ is additive decomposition formula, $\mathrm{Eq}(6)$ is multiplicative decomposition formula. The subscripts str and int respectively indicate the effects industry structure and power intensity[12,13].

\section{Decomposition Analysis of Electricity Consumption Intensity of High Energy-consuming Industries in Shanxi Province}

\subsection{Data and Variable}

The data sources are the "Statistical Yearbook of Shanxi Province", "China Economic Yearbook" and "China power statistical yearbook". Considering the limitation of data availability and research integrity, the research period is from 2006 to 2012.

There are seven high energy-consuming industries in Shanxi province, including Oil processing and coking and nuclear fuel processing industry (H1), Chemical raw materials and chemical products manufacturing (H2); Nonmetallic mineral products $(\mathrm{H} 3)$; Black metal smelting and rolling processing industry (H4); Non-ferrous metal smelting and rolling processing industry (H5); Electricity, heat production and supply industry (H6); Coal mining and washing industry (H7).

\subsection{The Decomposition of Electricity Consumption Intensity}

In this sector, on the basis of the electricity consumption intensity in 2006, the power consumption intensity of the seven high energy-consuming industries in Shanxi province from 2007-2012 are decomposed into structure effect and intensity effect based on LMDI model. The decomposition results are shown in Table 1.

Table 1. The decomposition results of electricity consumption intensity of high energy-consuming industries from 2006-2012.

\begin{tabular}{llll}
\hline years & total effect & structure effect & intensity effect \\
\hline 2007 & 143.19 & -163.54 & 306.74 \\
2008 & -903.74 & -1858.79 & 955.05 \\
2009 & -1002.77 & -2674.57 & 1671.81 \\
2010 & -1370.38 & -2105.61 & 735.23 \\
2011 & -1741.13 & -2192.53 & 451.40 \\
2012 & -1563.94 & -2064.36 & 500.42 \\
& proportion of & proportion of & proportion of \\
& total effect & structure effect & intensity effect \\
2007 & $100 \%$ & $-114.21 \%$ & $214.21 \%$ \\
2008 & $100 \%$ & $205.68 \%$ & $-105.68 \%$ \\
2009 & $100 \%$ & $266.72 \%$ & $-166.72 \%$ \\
2010 & $100 \%$ & $153.65 \%$ & $-53.65 \%$ \\
2011 & $100 \%$ & $125.93 \%$ & $-25.93 \%$ \\
2012 & $100 \%$ & $132.00 \%$ & $-32.00 \%$ \\
\hline
\end{tabular}

Unity: One billion kWh

As shown in table 1 , the electricity consumption intensity keep a trend of decline from 2007-2012. The structure effect promotes the decline of the electricity consumption intensity 
of the high energy-consuming industries, while the efficiency effect impedes the decline of the intensity. Moreover, the structure effect is far more than the intensity effect, which indicates that industry structure optimization is the main driving force which promotes the decline of electricity consumption intensity for seven high energy-consuming industries in Shanxi province.

\subsection{Structure Effect}

As shown in table 2, the structure effects of most industries are negative and declines during 2007-2012, which indicates that most industries promote the decline of consumption intensity. Meanwhile, the structure effect of Non-ferrous metal smelting and rolling processing industry (H5) is close to the structure effect of the total high energyconsuming industry, which is the most industry affect the consumption of the total industry. On the other hand, the structure effects of Non-metallic mineral products (H3) and Coal mining and washing industry $(\mathrm{H} 7)$ are positive, which promote the increasing of the consumption intensity of the industry.

Table 2. The structure effect of the decomposition results.

\begin{tabular}{|c|c|c|c|c|c|c|c|c|}
\hline Year & Total & H1 & H2 & H3 & H4 & H5 & H6 & H7 \\
\hline \multicolumn{9}{|c|}{ The value of structure effect } \\
\hline 2007 & 12.14 & 91.33 & -13.02 & 85.66 & -177.79 & -151.88 & -9.98 & 12.14 \\
\hline 2008 & 29.09 & -201.15 & -27.67 & -385.61 & -585.97 & -897.97 & 210.48 & 29.09 \\
\hline 2009 & -32.55 & -345.39 & 31.12 & -445.57 & -1491.45 & -693.14 & 302.41 & -32.55 \\
\hline 2010 & -39.78 & -287.72 & 22.69 & -447.68 & -867.59 & -776.69 & 291.17 & -39.78 \\
\hline 2011 & -76.07 & -287.72 & 19.13 & -387.84 & -844.86 & -923.4 & 308.22 & -76.07 \\
\hline 2012 & -113.09 & -258.79 & 32.68 & -504.09 & -884.76 & -670.41 & 334.11 & -113.09 \\
\hline \multicolumn{9}{|c|}{ The proportion of structure effect } \\
\hline 2007 & $-114.21 \%$ & $8.48 \%$ & $63.78 \%$ & $-9.09 \%$ & $59.82 \%$ & $-124.16 \%$ & $-106.06 \%$ & $-6.97 \%$ \\
\hline 2008 & $205.68 \%$ & $-3.22 \%$ & $22.26 \%$ & $3.06 \%$ & $42.67 \%$ & $64.84 \%$ & $99.36 \%$ & $-23.29 \%$ \\
\hline 2009 & $266.72 \%$ & $3.25 \%$ & $34.44 \%$ & $-3.10 \%$ & $44.43 \%$ & $148.73 \%$ & $69.12 \%$ & $-30.16 \%$ \\
\hline 2010 & $153.65 \%$ & $2.90 \%$ & $21.00 \%$ & $-1.66 \%$ & $32.67 \%$ & $63.31 \%$ & $56.68 \%$ & $-21.25 \%$ \\
\hline 2011 & $125.93 \%$ & $4.37 \%$ & $16.52 \%$ & $-1.10 \%$ & $22.28 \%$ & $48.52 \%$ & $53.03 \%$ & $-17.70 \%$ \\
\hline 2012 & $132.00 \%$ & $7.23 \%$ & $16.55 \%$ & $-2.09 \%$ & $32.23 \%$ & $56.57 \%$ & $42.87 \%$ & $-21.36 \%$ \\
\hline
\end{tabular}

\subsection{Efficiency Effect}

As can be seen from Table 3, the efficiency effects of most industries are opposite structure effects. The efficiency effects of most industries are promote the increasing of the consumption intensity for high energy-consuming industries. The efficiency effects of Non-ferrous metal smelting and rolling processing industry (H5) and Electricity, heat production and supply industry (H6) are close to the structure effect of the total high energy-consuming industry, which increase the electricity consumption intensity of high energyconsuming industries. The efficiency effects of other industries decline the consumption intensity. However, the proportion of the efficiency effect for these industries are far less than the Non-ferrous metal smelting and rolling processing industry (H5) and Electricity, heat production and supply industry (H6).

Table 3. The efficiency effect of the decomposition results.

\begin{tabular}{|c|c|c|c|c|c|c|c|c|}
\hline Year & Total & H1 & $\mathrm{H} 2$ & H3 & H4 & H5 & H6 & H7 \\
\hline 2007 & 306.74 & -2.22 & -142.64 & -9.92 & -7.73 & 333.28 & 146.34 & -10.37 \\
\hline 2008 & 955.05 & -44.21 & -22.29 & -30.19 & 221.40 & 491.28 & 685.11 & -346.05 \\
\hline 2009 & 1671.81 & -11.44 & 49.45 & -72.07 & 355.01 & 1244.09 & 510.09 & -403.33 \\
\hline 2010 & 735.23 & -8.74 & -104.20 & -73.80 & 298.79 & 587.71 & 489.94 & -454.47 \\
\hline 2011 & 451.40 & 38.48 & -142.21 & -67.11 & 129.85 & 506.39 & 508.61 & -522.61 \\
\hline 2012 & 500.42 & 67.41 & -134.92 & -84.77 & 315.59 & 500.44 & 339.23 & -502.56 \\
\hline 2007 & $214.21 \%$ & $-1.55 \%$ & $-99.61 \%$ & $-6.92 \%$ & $-5.40 \%$ & $232.74 \%$ & $102.20 \%$ & $-7.24 \%$ \\
\hline 2008 & $-105.68 \%$ & $4.89 \%$ & $2.47 \%$ & $3.34 \%$ & $-24.50 \%$ & $-54.36 \%$ & $-75.81 \%$ & $38.29 \%$ \\
\hline 2009 & $-166.72 \%$ & $1.14 \%$ & $-4.93 \%$ & $7.19 \%$ & $-35.40 \%$ & $-124.07 \%$ & $-50.87 \%$ & $40.22 \%$ \\
\hline 2010 & $-53.65 \%$ & $0.64 \%$ & $7.60 \%$ & $5.39 \%$ & $-21.80 \%$ & $-42.89 \%$ & $-35.75 \%$ & $33.16 \%$ \\
\hline 2011 & $-25.93 \%$ & $-2.21 \%$ & $8.17 \%$ & $3.85 \%$ & $-7.46 \%$ & $-29.08 \%$ & $-29.21 \%$ & $30.02 \%$ \\
\hline 2012 & $-32.00 \%$ & $-4.31 \%$ & $8.63 \%$ & $5.42 \%$ & $-20.18 \%$ & $-32.00 \%$ & $-21.69 \%$ & $32.13 \%$ \\
\hline
\end{tabular}

\subsection{Total Effect of each Industry}

The totla effect of each high energy-consuming industry is shown in table 4 , in which the totoal effec of Non-ferrous metal smelting and rolling processing industry (H5) is relative higher than other industries. The average contribution proportion is $35.29 \%$, and then is the Black metal smelting and rolling processing industry (H4) which 
has a contribution proportion of $19.63 \%$.

Table 4. The total effect of the decomposition results.

\begin{tabular}{|c|c|c|c|c|c|c|c|c|}
\hline Year & Total & H1 & $\mathrm{H} 2$ & H3 & H4 & H5 & H6 & H7 \\
\hline 2007 & 143.19 & 9.91 & -51.31 & -22.94 & 77.92 & 155.49 & -5.54 & -20.35 \\
\hline 2008 & -903.74 & -15.11 & -223.45 & -57.86 & -164.21 & -94.69 & -212.86 & -135.57 \\
\hline 2009 & -1002.77 & -43.99 & -295.94 & -40.95 & -90.56 & -247.36 & -183.05 & -100.91 \\
\hline 2010 & -1370.38 & -48.52 & -391.92 & -51.11 & -148.88 & -279.88 & -286.75 & -163.30 \\
\hline 2011 & -1741.13 & -37.59 & -429.93 & -47.97 & -257.99 & -338.46 & -414.80 & -214.39 \\
\hline 2012 & -1563.94 & -45.68 & -393.70 & -52.09 & -188.50 & -384.32 & -331.18 & -168.46 \\
\hline \multicolumn{9}{|c|}{ The proportion of structure effect } \\
\hline 2008 & $1.67 \%$ & $24.72 \%$ & $6.40 \%$ & $18.17 \%$ & $10.48 \%$ & $23.55 \%$ & $15.00 \%$ & $1.67 \%$ \\
\hline 2009 & $4.39 \%$ & $29.51 \%$ & $4.08 \%$ & $9.03 \%$ & $24.67 \%$ & $18.25 \%$ & $10.06 \%$ & $4.39 \%$ \\
\hline 2010 & $3.54 \%$ & $28.60 \%$ & $3.73 \%$ & $10.86 \%$ & $20.42 \%$ & $20.93 \%$ & $11.92 \%$ & $3.54 \%$ \\
\hline 2011 & $2.16 \%$ & $24.69 \%$ & $2.76 \%$ & $14.82 \%$ & $19.44 \%$ & $23.82 \%$ & $12.31 \%$ & $2.16 \%$ \\
\hline 2012 & $2.92 \%$ & $25.17 \%$ & $3.33 \%$ & $12.05 \%$ & $24.57 \%$ & $21.18 \%$ & $10.77 \%$ & $2.92 \%$ \\
\hline
\end{tabular}

\section{Conclusions}

In this paper, the LMDI method is used to decompose the electricity consumption intensity of high energy-consuming industries in Shanxi province, in which the impacts on the changes of electricity consumption intensity are divided into structure adjustment and efficiency promotion.

Through research and analysis, we find that the structure adjustment of Shanxi province is the main driver of declining the electricity consumption intensity for high energyconsuming industries. For most industries, the structure effects decline the intensity with a high contribution proportion. Meanwhile, Non-ferrous metal smelting and rolling processing industry (H5) is the most industry affect the consumption of the total industry. On the other hand, the structure effects of Non-metallic mineral products (H3) and Coal mining and washing industry (H7) are positive, which promote the increasing of the consumption intensity of the industry.

Meanwhile, the contribution proportions of efficiency effect for most industries are less than the corresponding structure effect. Non-ferrous metal smelting and rolling processing industry (H5) and Electricity, heat production and supply industry (H6) increase the electricity consumption intensity of high energy-consuming industries. The efficiency effects of other industries decline the consumption intensity. However, the proportion of the efficiency effect for these industries are far less than the Non-ferrous metal smelting and rolling processing industry (H5) and Electricity, heat production and supply industry (H6).

The totla effect of each high energy-consuming industry is shown in table 4 , in which the totoal effec of Non-ferrous metal smelting and rolling processing industry (H5) is relative higher than other industries, and then is the Black metal smelting and rolling processing industry $(\mathrm{H} 4)$.

In order to promote the smooth progress of energy conservation and emission reduction and drive the development of low carbon green economy in Shanxi province, this paper puts forward the following suggestions according to decomposition results:

(1) Transform economic growth mode and promote renewable energy power generation.

(2) Promote the optimization of industry structure adjustment, reduce the proportion in economy of high energy-consuming sectors and speed up the development of the tertiary industry.

(3) Introduce advanced electricity technology and management level, drive the use and upgrade of energysaving technology.

\section{Acknowledgments}

This study is supported by the Humanity and Social Science project of the Ministry of Education of China (Project number: 11YJA790217), the National Natural Science Foundation of China (Project number: 71373076), the Fundamental Research Funds for the Central Universities, and Science and Technology Project of State Grid Corporation of China (Contract number: SGHB0000DKJS1400116).

\section{References}

[1] Rose A, Chen C Y. Sources of change in energy use in the US economy, 1972-1982: a structural decomposition analysis[J]. Resources and Energy, 1991, 13(1): 1-21.

[2] Ang B W, Zhang F Q. A survey of index decomposition analysis in energy and environmental studies[J]. Energy, 2000, 25(12): 1149-1176.

[3] Azadeh A, Ghaderi S F, Sohrabkhani S. Annual electricity consumption forecasting by neural network in high energy consuming industrial sectors[J]. Energy Conversion and Management, 2008, 49(8): 2272-2278.

[4] Chan D Y L, Yang K H, Hsu C H, et al. Current situation of energy conservation in high energy-consuming industries in Taiwan[J]. Energy policy, 2007, 35(1): 202-209.

[5] Ang, B.W., Choi, K.H. 1997.Decomposition of aggregate energy and gas emission intensities for industry: a refined Divisia index method. Energy J. 18 (3): 59-73.

[6] Choi, K.H., Ang, B.W.. 2003. Decomposition of aggregate energy intensity changes in two measures: difference and ratio. Energy Economics 25: 615-624. 
[7] Chunbo Ma, DavidI.Stern. 2008. China's changing energy intensity trend: A decomposition analysis. Energy Economics, 30: $1037-1053$.

[8] Fengdan Shi. 2008. The analysis on cause of the changes of China's industrial energy consumption. Systems Engineering 04: 55-60.

[9] Yuhui Ou, Yifang Liu, Jiangyi Man. 2007.The decomposition of energy consumption growth in china based on LMDI. Economic Management Journal, 07.

[10] Zhengyu Gao, Yi Wang. 2007. Decomposition analysis of changes of Chinese production energy consumption. Statistical Research, 03.
[11] Zhiyong Han, Yiming Wei, Ying Fan. 2004. The research on characteristics of changes of Chinese energy intensity and economic structure. Journal of Applied Statistics and Management, 01.

[12] De Haan M. A structural decomposition analysis of pollution in the Netherlands[J]. Economic Systems Research, 2001, 13(2): 181-196.

[13] Achão C, Schaeffer R. Decomposition analysis of the variations in residential electricity consumption in Brazil for the 1980-2007 period: measuring the activity, intensity and structure effects[J]. Energy policy, 2009, 37(12): 5208-5220. 